\title{
PARAMETER OPTIMIZATION OF PREHEATING METHOD ON ALUMINIUM-STAINLESS STEEL METAL INERT GAS (MIG) DISSIMILAR WELDING
}

\author{
Mohamad Rusdi Abdul Rahman ${ }^{1, a}$, Luqman Hakim Ahmad Shah ${ }^{1, b}$ \\ and Mahadzir ${ }^{1, c}$
}

${ }^{1}$ Faculty of Mechanical Engineering, Universiti Malaysia Pahang, 26600 Pekan, Pahang, Malaysia.

air_rusdi88@yahoo.com, 'bluqmanhakim@ump.edu.my, 'cmahadzir@ump.edu.my

Keywords: Aluminium, Stainless steel, Dissimilar, Joining, Welding, Preheating, Taguchi method

\begin{abstract}
This paper investigates the parameter optimization of a preheating method on stainless steel SUS304 prior to aluminium-stainless steel dissimilar welding. The welding method used was metal inert gas (MIG) with butt joint type weld. The Taguchi L9 orthogonal array was used to investigate the optimum parameter, while the mechanical strength was investigated using tensile test. Optimum levels of the process parameters were analyzed using the Taguchi parametric design approach. Parameter analysis of the tensile test results indicate that the preheated specimen with 90 ${ }^{\circ} \mathrm{C}$ have the maximum ultimate tensile strength of $111.27 \mathrm{MPa}$. This value is in close proximity to the calculated value of $109.02 \mathrm{MPa}$ with $2 \%$ error. Through analysis of variance (ANOVA), the welding current was the dominant contributing factor with $40 \%$. It can be concluded that the highest tensile value (111.27 MPa) for AA6061-SS304 dissimilar welding was obtained using $90{ }^{\circ} \mathrm{C}$ preheating, voltage of $17.5 \mathrm{~V}$ and current of $110 \mathrm{~A}$ of current.
\end{abstract}

\section{Introduction}

Metal inert gas (MIG) welding is a prominent fusion welding method and is widely used in various industrial applications such as in shipbuilding, construction and automotive sector. To meet new industrial demands, a new welding technique known as dissimilar welding was introduced in the market. Such technique opens the possibilities to join metals of dissimilar alloy or material together to form a unique part. Dissimilar welding research have seen many successful joining of different materials to aluminium, such as aluminium to steel [1], aluminium to copper [2], aluminium to magnesium [3] and aluminium to titanium [4]. Out of the many combinations, dissimilar welding between aluminium and various steel alloys has been one of the most widely studied upon. This is primarily due to the high strength and toughness characteristics of steel alloys that compliments well with the low cost, light weight and corrosion resistant characteristic of aluminium alloys [5], [6].

However, such combination is difficult due to the near zero solubility and the stark contrast of the melting temperature between aluminium and steel. Consequently, this facilitates the formation of a notorious $\mathrm{Fe}_{\mathrm{x}} \mathrm{Al}_{\mathrm{y}}$ brittle intermetallic (IMC) compound between the two metals during welding [7], [8].

To mitigate the formation of such brittle structure, several researches have proposed the use of preheating prior to the welding process. Shah et al. [9] and Razak [10] have conducted the preheating method on tungsten inert gas (TIG) dissimilar welding AA1100-SUS304 and AA6061SUS304, respectively, and both results have shown an increase in the tensile strength of the joint when steel is preheated up to $150{ }^{\circ} \mathrm{C}$. Other researches by Kreimeyer and Vollertsen [11] as well as Bang et al. [12] also suggested a secondary heat source in order to preheat the steel counterpart prior to welding to enhance the joint strength output.

However, most of the papers mentioned above did not report on how the crucial welding parameters were systematically chosen to perform the task. It is therefore important that parameter optimization using parametric design and statistical means needs to be utilized in order to produce a 
replicable outcome [13][14]. In this research, the Taguchi parametric design was utilized to perform AA6061-SUS304 MIG dissimilar butt joint welding with the preheating method in order to investigate the optimum welding parameter for the best joint quality.

\section{Experimental method}

The base materials used in this experiment are AA6061 aluminium alloy and SUS304 stainless steel alloy. Both materials were cut into $150 \times 55 \times 2 \mathrm{~mm}$ dimensions. The filler metal used was aluminium-based ER4043. The chemical compositions of both base metals and filler metal are shown in Table 1.

Table 1. Chemical composition of base metal AA6061 and SUS304 (wt.\%)

\begin{tabular}{lllllllll}
\hline Composition & $\mathrm{Mg}$ & $\mathrm{Si}$ & $\mathrm{Mn}$ & $\mathrm{Fe}$ & $\mathrm{Cu}$ & $\mathrm{Cr}$ & $\mathrm{C}$ & $\mathrm{Al}$ \\
\hline AA6061 & 0.775 & 0.643 & 0.073 & 0.303 & 0.236 & 0.191 & - & Balance \\
SUS304 & - & 0.397 & 1.01 & 71.4 & 0.21 & 17.9 & 0.06 & 0.004 \\
ER4043 & 0.05 & 5.0 & 0.05 & 0.3 & 0.12 & - & - & Balance \\
\hline
\end{tabular}

The joining process was carried out by using an automated welding apparatus utilizing the Dr Well DM-500EF MIG welding machine. Once the base metals are clamped accordingly, a mobile torch was employed to preheat the stainless steel sheet to the desired temperature. An electronic thermometer was used to monitor the elevated temperature. After it has reached the desired temperature, butt joint type MIG welding was immediately commenced. All fabricated specimen were cut into the standard dog bone shape using the American Society for Testing of Materials (ASTM E8-09) guidelines and underwent tensile testing to evaluate the specimen's strength.

In order to investigate the optimum welding parameters, a Taguchi L9 orthogonal array (OA) was utilized. The preheating temperature as well as the welding's voltage and current are set as the main parameters to observe. Table 2 shows the three levels for the three factors.

Table 2. Three levels of preheating temperature, voltage and current.

\begin{tabular}{cccc}
\hline Factors & Level 1 & Level 2 & Level 3 \\
\hline Preheating temperature $\left({ }^{\circ} \mathrm{C}\right)$ & 90 & 180 & 270 \\
Voltage $(\mathrm{V})$ & 17 & 17.5 & 18 \\
Current $(\mathrm{A})$ & 105 & 110 & 115 \\
\hline
\end{tabular}

\section{Results and discussion}

Fig. 1 shows the weld appearance for the different temperature groups. All samples show good quality joints with minimal weld defects, with Figure 1(a) (preheating of $90{ }^{\circ} \mathrm{C}$ ) showing the best overall appearance.
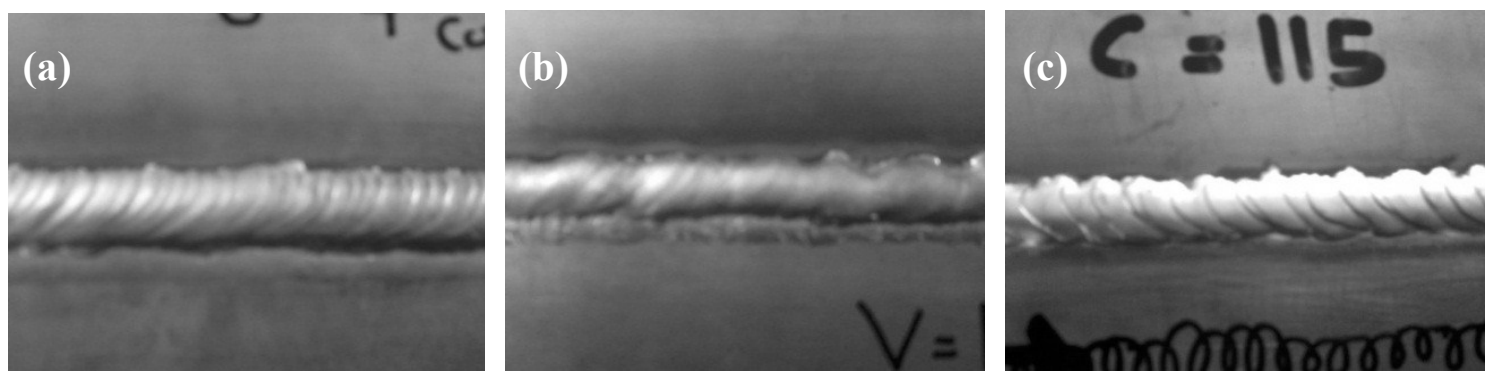

Fig. 1. Weld appearance of specimen with preheating temperature of (a) $90{ }^{\circ} \mathrm{C}$ (b) $180{ }^{\circ} \mathrm{C}$ (c) $270{ }^{\circ} \mathrm{C}$. 
From the tensile test values, the larger-the-better $\mathrm{S} / \mathrm{N}$ ratio can be calculated using Eq.1;

$$
S / N=\eta_{d B}=10 \log \left[\frac{1}{\frac{1}{n} \sum_{i=1}^{n} \frac{1}{Y_{i}^{2}}}\right]=-10 \log \left(\frac{1}{n} \sum_{i=1}^{n} \frac{1}{y_{i}^{2}}\right) .
$$

where the $n$ represents the number of test and $y_{i}$ is the experimental value [15]. Table 3 below shows the tensile strength mean value and $\mathrm{S} / \mathrm{N}$ ratio for the $\mathrm{L} 9$ orthogonal array.It can be seen that the highest mean value is from specimen 2 with $111.27 \mathrm{MPa}$ with $90{ }^{\circ} \mathrm{C}$ preheating temperature (level 1), $17.5 \mathrm{~V}$ welding voltage (level 2) and $110 \mathrm{~A}$ welding current (level 2).

Table 3. Tensile strength mean value and $\mathrm{S} / \mathrm{N}$ ratio for L9 orthogonal array

\begin{tabular}{cccccc}
\hline \multirow{2}{*}{ Experiment } & \multicolumn{3}{c}{ Joining Parameters } & & \\
\cline { 2 - 4 } & $\begin{array}{c}\text { Preheating } \\
\text { temperature }\left({ }^{\circ} \mathrm{C}\right)\end{array}$ & $\begin{array}{c}\text { Voltage } \\
(\mathrm{V})\end{array}$ & $\begin{array}{c}\text { Current } \\
(\mathrm{C})\end{array}$ & Mean value (MPa) & S/N ratio \\
\hline 1 & $\mathbf{9 0}$ & 17 & 105 & 104.53 & 40.385 \\
2 & $\mathbf{9 0}$ & $\mathbf{1 7 . 5}$ & $\mathbf{1 1 0}$ & 111.27 & 40.928 \\
3 & $\mathbf{9 0}$ & 18 & 115 & 66.46 & 36.451 \\
4 & 180 & 17 & 115 & 95.04 & 39.558 \\
5 & 180 & $\mathbf{1 7 . 5}$ & 105 & 88.34 & 38.923 \\
6 & 180 & 18 & $\mathbf{1 1 0}$ & 89.28 & 39.015 \\
7 & 270 & 17 & $\mathbf{1 1 0}$ & 60.53 & 35.639 \\
8 & 270 & $\mathbf{1 7 . 5}$ & 115 & 80.97 & 38.166 \\
9 & 270 & 18 & 105 & 82.67 & 38.347 \\
\hline
\end{tabular}

The analysis above has shown the best parameter levels to achieve maximum tensile strength (highligthed in bold). Through this method, the optimum value of the tensile strength can be calculated using Eq. 2 below;

Tensile strength $(\mathrm{MPa})=P T_{1}+W V_{2}+W C_{2}-2 T$.

$$
=104.52+111.266+111.266-(2 \times 109.02)=109.02 \mathrm{MPa} .
$$

where $P T_{1}$ is the average tensile strength at $90{ }^{\circ} \mathrm{C}$ preheating temperature; $W V_{2}$ is the average tensile strength at $17.5 \mathrm{~V}$ voltage; $W C_{2}$ is the average tensile strength at $110 \mathrm{~A}$ current; and $T$ is the overall mean of the tensile strength. Substituting the values calculated from Table 3, the highest tensile value was calculated to be $109.02 \mathrm{MPa}$.

Since the combination of $P T_{1}, W V_{2}$ and $W C_{2}$ has already been conducted (sample 2), this value was found to be in excellent proximity to the experimental value of $111.27 \mathrm{MPa}$ with only $2 \%$ error. The analysis of variance (ANOVA) was also conducted and show that the percentage of factors contribution was found to be, in descending order; current (47\%), preheating temperature $(30 \%)$, voltage $(14 \%)$ and error $(9 \%)$. Current and preheating temperature was proven to be the dominant factor.

\section{Conclusion}

Dissimilar metals joints between AA6061 aluminum alloy and SUS304 stainless steel alloy were fabricated using MIG welding to investigate the parameter optimization analysis using the Taguchi method. All specimen show good weld appearance with minimal weld defects. The best weld appearance was from sample 2, with preheating $90^{\circ} \mathrm{C}$, voltage $17.5 \mathrm{~V}$ and current $110 \mathrm{~A}$. Consequently, sample 2 also obtained the highest tensile strength of $111.27 \mathrm{MPa}$. Using the same factor levels, the calculated highest tensile value was shown to be $109.02 \mathrm{MPa}$, which is in excellent proximity to the experimental value with $2 \%$ error. Through ANOVA, welding current was found to be the dominant contributing factor with $40 \%$. 


\section{References}

[1] M. J. Rathod, M. Kutsuna, Joining of Aluminum Alloy 5052 and Low-Carbon Steel by Laser Roll Welding, J. Weld. 83 (2004) 16-26.

[2] T. Saeid, a. Abdollah-zadeh, B. Sazgari, Weldability and mechanical properties of dissimilar aluminum-copper lap joints made by friction stir welding, J. Alloys Compd. 490 (2010) 652-655.

[3] Y. J. Kwon, I. Shigematsu, N. Saito, Dissimilar friction stir welding between magnesium and aluminum alloys, Mater. Lett. 62 (2008) 3827-3829.

[4] U. Dressler, G. Biallas, U. Alfaro Mercado, Friction stir welding of titanium alloy TiAl6V4 to aluminium alloy AA2024-T3, Mater. Sci. Eng. A 526 (2009) 113-117.

[5] S. Fukumoto, H. Tsubakino, K. Okita, M. Aritoshi, T. Tomita, Amorphization by friction welding between 5052 aluminum alloy and 304 stainless steel, Scr. Mater. 42 (2000) 807-812.

[6] M. Staubach, S. Juttner, U. Fussel, M. Dietrich, Joining of steel-aluminium mixed joints with energy-reduced GMA processes and filler materials on an aluminium and zinc basis, Weld. Cut. 7 (2008) 30-38.

[7] C. Dharmendra, K. P. Rao, J. Wilden, S. Reich, Study on laser welding-brazing of zinc coated steel to aluminum alloy with a zinc based filler, Mater. Sci. Eng. A 528 (2011) 1497-1503.

[8] R. Qiu, C. Iwamoto, S. Satonaka, The influence of reaction layer on the strength of aluminum/steel joint welded by resistance spot welding, Mater. Charact. 60 (2009) 156-159.

[9] L. H. Shah, A. S. M. Yusof, M. Ishak, Investigation of heat treatment on weld joint quality of stainless steel and aluminium dissimilar welding, Proceedings of the 16th International Conference on Advances in Materials \& Processing Technologies (AMPT'14) (2013).

[10] M. N. A. Razak, Investigation of heat treatment (preheat) of steel on aluminium-steel welding, Degree thesis, Universiti Malaysia Pahang (2013).

[11] M. Kreimeyer, F. Vollertsen, Gap tolerant joining of aluminium with steel sheets using the hybrid technique, Proceedings of International Congress on Applications of Lasers and ElectroOptics 2006 (ICALEO’06) (2006) 947-952.

[12] H. Bang, H. Bang, G. Jeon, I. Oh, C. Ro, Gas tungsten arc welding assisted hybrid friction stir welding of dissimilar materials A16061-T6 aluminum alloy and STS304 stainless steel, Mater. Des. 37 (2012) 48-55.

[13] D. C. Montgomery, Design and Analysis of Experiments, forth ed. John Wiley \& Sons, New York, 2006.

[14] A. K. Lakshminarayanan, V. Balasubramanian, Process parameters optimization for friction stir welding of RDE-40 aluminium alloy using Taguchi technique, 18 (2007) 2-8.

[15] P.J. Ross, Taguchi techniques for quality engineering, second ed., McGraw Hill Professional, New York, 1996. 